\title{
A longitudinal study on the promotion of acquisition processes in the EFL classroom: theoretical proposals and practical implications
}

\author{
JAVIER GARCía JimÉNEZ \\ IES Monterroso (Estepona, Málaga)
}

Received: 11-1-07 / Aceptado: 10-04-07

ISSN: $1697-7467$

\begin{abstract}
The framework that Relevance Theory offers for the description of the internal processes involved in comprehension, and its incorporation into SLA studies by Haidl (1993), enable this author to present a range of innovatory methodological guidelines aiming to achieve acquisition in the FL classroom. Following these guidelines, the longitudinal study which we report here aims to test the development of acquisition in that context. The results show the practicality of the project and reveal the possible incompatibility of combining acquisition and learning processes in the classroom if it is not approached from a consistent theoretical basis.
\end{abstract}

Keywords: foreign language acquisition, relevance theory, foreign language teaching methodology, conscious reflection on language, motivation.

\begin{abstract}
RESUMEN: El marco que ofrece la Teoría de la Relevancia para describir los procesos internos que intervienen en la comprensión y su incorporación a los estudios de ASL por Haidl (1993) permiten a este autor presentar una serie de orientaciones metodológicas para generar adquisición en el aula de LE. Siguiéndolas, el estudio longitudinal que aquí comentamos intenta desarrollar adquisición en el aula de la ESO. Los resultados muestran la practicidad del proyecto y revelan la posible incompatibilidad de combinar en el aula procesos de adquisición y aprendizaje si el recurso a la reflexión consciente no se aborda desde bases teóricas consecuentes.

Palabras clave: adquisición de una lengua extranjera, teoría de la relevancia, didáctica de lenguas extranjeras, reflexión consciente en el uso del lenguaje, motivación.
\end{abstract}

This article is a succinct report of J. García Jiménez's doctoral thesis La Adquisición de una Lengua Extranjera en el Aula de la ESO (Classroom FL Acquisition in Secondary Education), a research undertaken during the school year 2003-2004 to study the feasibility of generating acquisition in the FL classroom. The study starts out from a detailed theoretical position, where acquisition is understood to be as defined by Krashen's dichotomy, that is to say, as the natural, intuitive and unconscious development of language or the way children assimilate their L1, and in opposition to learning or the conscious study of a language as formal and explicit knowledge (Krashen 1981). Our main theoretical tenets are Haidl's contributions to the description of the internal processing of information in contexts of Foreign Language Acquisition (FLA), following the framework offered by Relevance Theory (Haidl 1993, 1995, 
2003). This perspective allows Anton Haidl to propose significant methodological implications aimed towards the generation of acquisition in the FL classroom. Our research is an attempt to put into practice these methodological directives, which we adapted to a course of English as a FL in the Spanish secondary education context (ESO) ${ }^{1}$. For that purpose, a one-year school syllabus was designed and a complete range of materials prepared. We then implemented the project as a nine month longitudinal experiment. The conclusions of our research emphasize the urgency of paying careful attention to the differences between both processes of linguistic development- acquisition and learning- in the classroom.

This article is divided into six sections: 1) Theoretical Approach, 2) Methodological Implications, 3) The Design of the Materials, 4) The Design of the Experiment, 5) Results and 6) Conclusions.

\section{Theoretical APPROACH}

Researchers already assume that acquisition can also take place in the FL classroom (Lightbown 2000, p. 439). But after Krashen's frequently criticized proposals and the mixed bag of the communicative approach, there is at present'no theoretical framework clearly endorsing this possibility or any consistent set of methodological directives fostering these objectives with practicality. This lack of guidelines underlines the importance of Haidl's work in this respect. In this section we will try to place this author's theory into the current literature.

Haidl's theoretical assumptions are grounded in the long-standing academic tradition of SLA studies and openly contribute to promote the co-existence of mentalist, interactionist and cognitive tenets ${ }^{2}$. This interpretation starts from a Chomskian concept of language, described as a human capacity which is:

- innate and creative, i.e.: that behaves as a universal grammar (UG).

- independent from human general cognitive abilities, and

- intuitive, i.e.: not normally needing conscious attention to its form in order to develop, as it automatically unfolds by participating in communication.

On the contrary, the human ability for conscious reflection on language is considered a different faculty and part of human general cognitive abilities. As it is obvious that individuals use their ability for linguistic reflection in varying degrees and with very different results, conscious reflection should not be understood as an essential component of the natural development of language. And although the interface between both types of knowledge, learned and acquired, is rather controversial ${ }^{3}$ and some critics think that learned knowledge

1 These methodological directives have already been seen in some projects with university students, namely, Haidl (1995) with absolute beginners of German and Bocanegra (1995) with ESP learners.

${ }^{2}$ Jordan (2004) makes an energetic call for new proposals to avoid the extremes of nativism versus empiricism and to try to go beyond Chomsky's scope.

${ }^{3}$ We find support of the non-interface position in Wode (1981), Felix (1981), Krashen (1982) and Pienemann (1984). On the side of interface we find McLaughlin (1978), Bley-Vroman (1988), Sharwood-Smith 
is automated through practice, Haidl agrees with Krashen that learners only benefit from monitoring ${ }^{4}$ their production with written texts, not during oral interaction.

Concerning the Universal Hypothesis, Haidl's interpretation adopts a position of continuity, which means that UG is considered to be available at any moment in the learner's life, even for the development of an L2/FL. Actually, Haidl shares Wode's opinion that when a faculty is not used it becomes gradually less accessible and atrophies but the UG is still there (Wode 1990). From this point of view, thoughtless promotion of conscious reflection in the classroom without analyzing the internal processes which this habit generates can be counter-productive, as learners get used to relying on their general cognitive abilities, while the processes and strategies leading to natural acquisition relax and atrophy.

The role of the L1 in the development of an L2/FL is interpreted by Haidl as a cognitive strategy ${ }^{5}$ to which the learner resorts, mainly during the early phases of development and in a more or less conscious way, so that the role of this strategy in the development of an L2/ FL would be very limited and its use should be considered as counter-productive again.

With regard to individual differences, the aptitude for the acquisition of an L2/FL is generally thought to be equal for everyone. However, attitude and motivation are widely seen as the main source of individual differences in the development of an L2/FL. Consequently, preferential attention to methodology should be given to the different dimensions of the concept of motivation ${ }^{6}$, particularly in FLA contexts.

Nevertheless, the main novelty in Haidl's interpretation is the description of the internal processing of input. For that purpose, Haidl incorporates the model of Relevance Theory (RT) into SLA studies, assuming that the most important process that takes place in language development is the formulation of hypotheses. He uses the same arguments as Sperber and Wilson (1986) regarding the factors and conditions that influence the interpretation of utterances in communication (graph 1), and analyzes them in the Foreign Language Acquisition (FLA) context.

\footnotetext{
(1981) and Zobl (1985). The so-called weak interface position is supported by Seliger (1979), Bialystok (1988), Ellis (1990) and Larsen-Freeman and Long (1991), for whom conscious knowledge would be a facilitator for the processes of acquisition.

${ }^{4}$ The concept of monitoring as in Krashen (1981).

${ }^{5}$ In agreement with Corder (1978).

${ }^{6}$ García Jiménez (2004) includes up to 7 interpretations of the concept of motivation as related to FL development.
} 
Graph 1. Internal input processing according to Sperber and Wilson (1984).
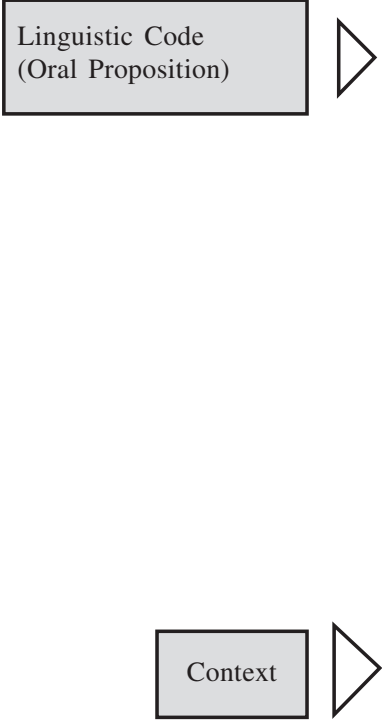

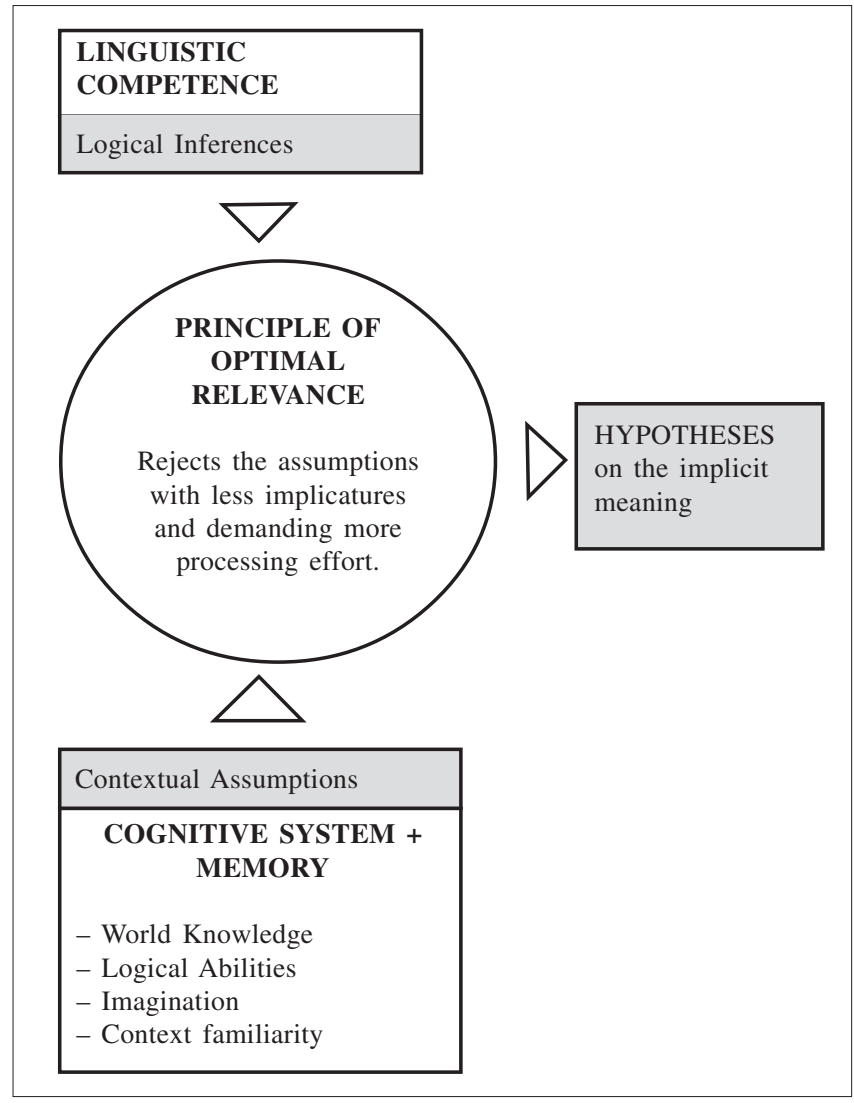

In this way, and closely following Sperber and Wilson's arguments, the hearer would ideally interpret an utterance when she/he presupposes that the message received is going to be relevant. In other words, the message is best understood when the hearer assumes that the speaker has made an ostension that the message is expressly addressed to her/him and that it calls for her/his individual interest. At the same time, the utterance will be even more relevant the more inferences on its implicit meaning it is able to raise in the hearer. These inferences are called implicatures. Finally, the most relevant implicatures are those giving rise to more contextual effects and demanding less processing effort. The implicatures giving rise to more contextual effects are those implicatures which better connect with the previous assumptions that the hearer has made from the observation of the context; the implicatures demanding less processing effort are those which better relate to the hearer's previous linguistic knowledge and imagination and are related to a psychologically uncomplicated proposition. 
Summing up, successful communication is provided by utterances which are easy to interpret. This happens when the hearer is able to infer what the speaker means and not just by recognizing the meaning of the proposition used. Consequently, comprehension is described as the result of making inferences both from the linguistic code of the oral expression and from the scale of assumptions that the context affords. Considering that in the early stages of FL development learners cannot but rely mainly on the second, Haidl finds here also the arguments to describe the kind of input and conditions fostering acquisition in SLA/FLA contexts.

Applying the RT principles, Haidl underlines that the FL learner does not only make assumptions on the intention of the speaker, she/he also makes them on the FL linguistic code, helped by her/his interlanguage grammar. If the learner's conclusions are especially relevant, she/he does not need to go on formulating any further hypotheses or to exhaust all the possible logical combinations to generate a norm. The learner simply adopts the one which, subjectively and according to her/his previous knowledge, seems to be more credible and less complex. Once a hypothesis is accepted, it becomes part of the learner's interlanguage as an active rule. These hypotheses that the individual incorporates into her/his interlanguage are confirmed later by means of trial and error during interaction. To complete the theoretical exposition, Haidl emphasizes that when all this process is done in a natural way, that is to say, by taking part in communication and without conscious reflection, then it does not demand any special effort from memory.

Graph 2. Input Processing by absolute beginners.

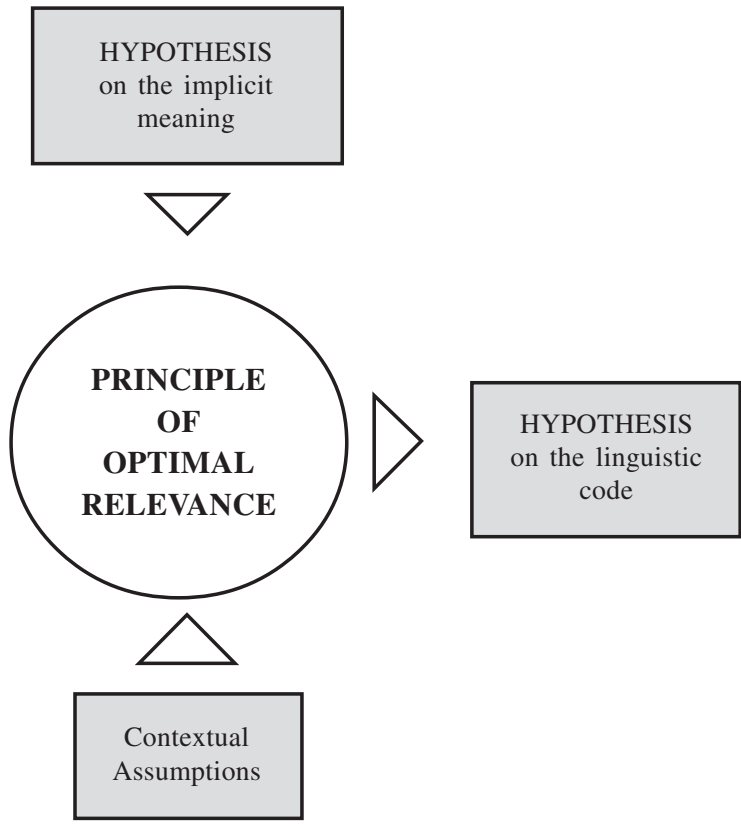


Since absolute beginners lack any FL linguistic code, they can only rely on their hypotheses for the implicit meaning of the utterance and on their contextual inferences to disambiguate the message (graph 2). It will be further on, when learners begin to develop their interlanguage, that they will be able to raise hypotheses on new linguistic parameters from their previous linguistic knowledge (graph 3).

Graph 3. Input Processing by false beginners.

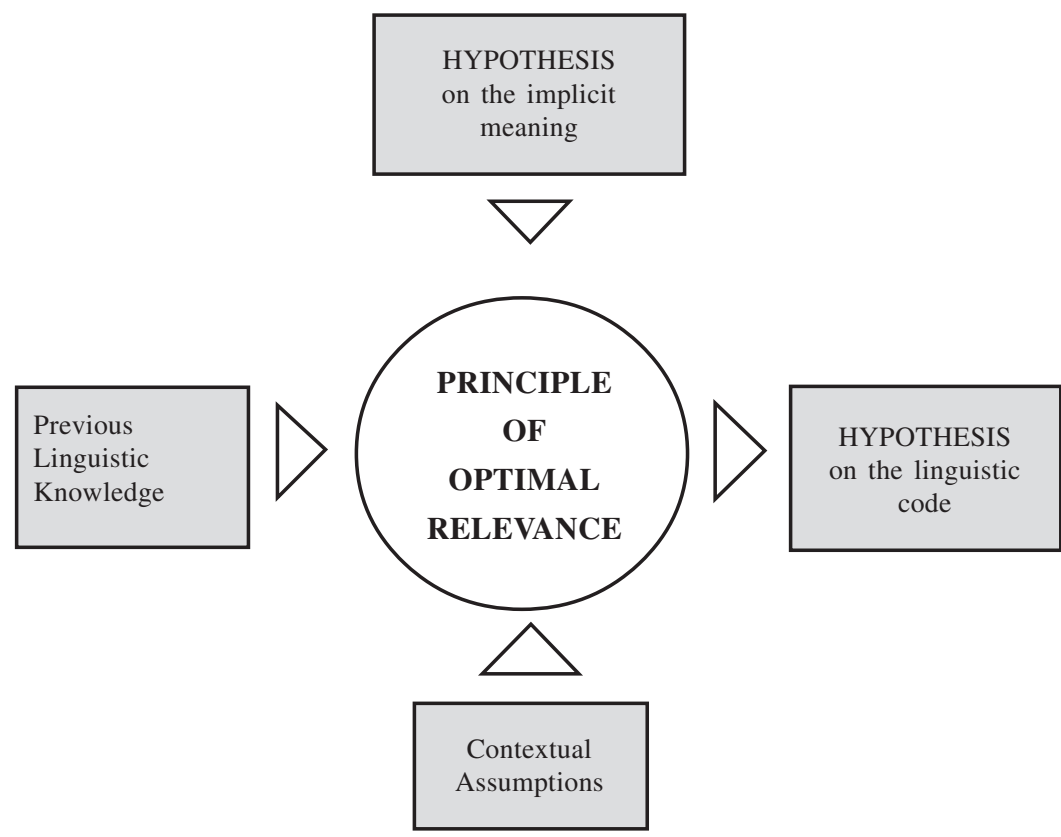

As a consequence, we think it is fundamental to consider the significance of contextual inferences in the design of a methodological frame for classroom FLA. The topic gains even more importance since the main difference between L2 and FL development relies mostly on the conditions of input accessibility. These conditions should include ostension during oral interactions, individual relevance of input, a rich referential context, connection with learners' previous knowledge and motivation to use exclusively the target language. As long as these circumstances can be reproduced in the classroom, Haidl affirms, we will be able to generate acquisition processes. The main purpose of our research was to quantify this possibility with EFL learners.

It is worth considering that although our intention to generate acquisition in the classroom and to explore facilitating procedures is clearly justified, it should also be noted that the conditions of access to input in L2 development contexts are clearly different from the FL development situation and that a similar degree of progress cannot be expected. 


\section{Methodological implications}

So far we have commented on the theoretical considerations from the SLA literature. We still need to see how these arguments can be transferred to L2 teaching methodology. According to Haidl, the main step to be taken to obtain acquisition in the FL classroom should be to adapt the context to the characteristics of natural communication. Haidl (1995) himself includes and tries a wide range of methodological implications from his theoretical model of SLA, and while these are not part of our contributions, we will briefly sum up here below those tenets to which we strictly adhered in our investigation. We still have to prove whether they are also valid for our context, comprised of 14 year-old beginners of English.

Haidl's basic methodological guidelines can be summed up as follows:

1. Only the target language must be used for communication in the classroom. Learners should try to survive relying on their linguistic knowledge and communicative strategies.

2. The main conversation topic should be the very context of the classroom and the here-and-now, as this facilitates the generation of contextual inferences and minimizes the processing effort. As inference is a highly subjective mental process, it is necessary to provide a highly referential, learner-familiar context and use topics coming from the learners' existential experience, their knowledge of the world and their real interests, rather than from their linguistic knowledge, especially during the earliest phases.

3. The oral input existing in the classroom to transmit and/or to negotiate the information comes mainly from the teacher and from the communicative interactions between learners. This input must be relevant to the learner. Therefore, it must bear an ostension of relevance and raise as many subjective implications as possible.

4. Ellis's interactions with activity oriented goals, framework goals and social goals ${ }^{7}$ are especially suitable for the classroom.

5. The teacher should facilitate input comprehension and roughly adapt his/her speech to the learners' level, resorting even to pragmatic resources such as body-language or mime.

6. The development of procedural knowledge should be promoted, including training on communicative, production and learning strategies.

7. Since each learner's interlanguage develops at a different pace, the syllabus for the classroom should not follow a grammatical sequence and learners should be given enough time to generate hypotheses on the linguistic code without demanding production till then.

8. It is fundamental to avoid any activity that encourages linguistic reflection in the classroom and to try to strengthen the learners' skills to cope with language instinctively and unconsciously. Nevertheless, advantage could also be taken of the learner's

${ }^{7}$ Ellis (1988, p.101) distinguishes among interactions with framework, core, and social goals. Core interactions can have in turn a medium, message or activity-oriented goal. Ellis's study on interactions in the L2 classroom is a sound contribution to speech analysis from a motivational point of view, as it is based on the goals that originate every interaction. 
ability to use academic skills already developed for reflection on language, provided that this does not interfere with the process of recovery of the natural strategies which we are pursuing in the classroom. Consequently, activities leading to conscious learning, especially reading, grammar and writing exercises should be set as homework.

9. The organization of the course should promote learners' commitment with the methodology proposed.

\section{ThE DESIGN OF THE MATERIALS}

After this succinct overview of the literature behind our research, and once we have presented a set of methodological directives coherent with the theoretical bases we adhere to, I will proceed with our contributions proper. Basically, we had to shape the curriculum for a full course, decide on the components and contents, and devise a timetable, making sure that the role of the teacher, the input and interactive materials fitted with these directives and with the range of subjects we wanted to apply them to.

Accordingly we will focus this section on the description of 1) how we distributed the contents temporally, and 2) the nature of the activities we used.

\subsection{The distribution of the contents}

The first step we took was to distribute the curriculum contents into three different classroom formats used on a weekly basis, namely:

1) The acquisition classroom, where we exploited the activities specially designed to generate acquisition. This format occupied two-thirds of the school hours.

2) The additional input classroom, where we used video films, listening practice, readings and presentations, in order to include in the course the kind of input that is not possible to reproduce in the classroom with any guarantee of relevance, meaning the input that usually appears in those activities not relating to the learner as an individual or those which relate to a different context such as the airport, a restaurant or a hotel. This format took one-sixth of the school hours.

3) The monitoring classroom, where we supervised the learners' homework. For homework the students had to complete a workbook with brief explanations and exercises following a grammatical syllabus, a selection of readings, and exercises for the development of written expression. Relegating for homework the tasks which involve conscious reflection on the use of language strictly safeguards the environment of the classroom for the recovery of acquisition processes. ${ }^{8}$ This format took the remaining one-sixth of the school hours.

${ }^{8}$ Undoubtedly the ideal support for this kind of tasks is computer software. With the suitable software it is possible to reduce significantly the time dedicated to these tasks in the classroom. Our study makes a strong case for the development of this type of materials as they ease the burden on the teacher when it comes to checking repetitive exercises or writing progress reports. As a result, they allow the teacher to concentrate on the more creative activities that her/his role demands. 


\subsection{The nature of the activities}

Even though the experiment showed that the three formats produced satisfactory contexts for generating acquisition, it was in particular the acquisition classroom the one which included the activities most closely related to the methodological proposals of the programme ${ }^{9}$. These activities had to be conceptually simple, be meaning-centred, bidirectional -preferably between learners-, to demand the negotiation of meaning, and in particular, they had to be focused in the here-and-now of the classroom and in the learners' reality, so that they could be personally relevant. There is a very interesting series of publications on the market ${ }^{10}$ from which to extract ideas for their elaboration. Nevertheless, to make them really functional, the activities had to involve the learners in a personal way, reflect their real physical environment and propose interactions having a real presumption of relevance to them. Thus, when they were offered, for example, a map to indicate directions, this map was a chart of their own school or village and they brought photos from their own familiar environment when they were required to describe a picture. The presumption of relevance is one of the most marked differences between the activities proposed in our research and those ordinarily appearing in a communicative manual.

García Jiménez (2004) suggests a long series of possible frameworks for the design of these types of activities. They would include social activities allowing for a relaxed atmosphere in the classroom, talk-about-yourself activities, competitions, contests, picture description, memorization and imagination activities, problem-solving tasks and tasks demanding the negotiation of meaning. Other possibilities are mime, giving or receiving instructions, guessing, completing or producing questionnaires, preparing interviews or doing activities which begin with reading or lead to drafting a writing text. As these activities all had a goal in themselves, we simply called them games.

To give a clear idea of the differences between the way the information is processed in our exercises and the way it is done in a communicative task, as for example a role-play, we have considered it interesting to analyse both with some thoroughness. Let us imagine a roleplay involving, for example, buying a CD in a music shop. Initially the students could listen to a tape and try to deduce what the characters say to each other. Later, they read the text, the teacher comments on the new structures, using the blackboard, and they practise some writing exercises. Finally the learners take the dialogue home for revising because on the next day they will have to perform it in class. In this following class, two students act out the situation. One may be trying hard to remember the script looking up at the ceiling and the other one may be looking for help from the last row, waiting for a hint from her/his classmates. Actually, it may not always be like this but is clear that it is a memorizing exercise. Communicative strategies are not being used. The context is fiction and there are no real communicative needs. In addition, there is no previous situation. Nothing is known about the characters, their relationships or tastes, and what is more important, what the learners tell

${ }^{9}$ Although in this article the focus is on the presentation of the activities proposed for this class format, our research also focused on other components of the curriculum, namely, teacher's speech, teacher's role, learning strategies, motivation, conscious learning treatment, classroom dynamics, the role of the didactic material and evaluation.

${ }^{10}$ For example, Lee (1979), Ur (1988), or Wright (1995). 
each other does not affect them in any way. This is why we believed that simulations were not relevant for our purposes.

Instead of that, we would suggest activities such as organizing a flea market for second hand CDs in the classroom. The first day, the teacher may ask one or two students to bring several CDs which they want to swap and the next day the teacher may make them all pay attention to the way she/he tries to swap her/his own CD for one from a student. Then the teacher can repeat it with another student. After that the teacher may write the sentences they have used on the blackboard and the students will presumably write them down in their notebooks to revise them at home so that they are able to swap something themselves the next day in their flea market classroom. In the additional input class, the teacher can also offer, in video format, conversations of people exchanging things. On the day of the flea market, learners should display their goods and walk around in the classroom searching and deciding what to exchange. The teacher may even try to get involved in the conversations. Someone may try to exchange her/his favourite CD for two. The teacher should walk around helping whoever wants it. Students can also help each other. It doesn't matter if they do it wrong. They can also communicate with signs as even mime is allowed. The teacher should only call the attention of those using the L1.

Over the whole process there may have been some memorization, but it is not all. Learners have a previous contact with the linguistic forms they are going to use in a full-ofreference context. They know their teacher and their schoolmates and are able to hypothesize on each other's intentions. At the moment of communicating they are not actors, they are themselves. Messages are personally addressed and clearly ostensible and referenciality is, therefore, high. The requirement of relevance is complete and the effort to infer the intentions minimal.

These games or tasks with a purpose in themselves are in turn suitable for being grouped around a single aim, shaping a sequence of tasks that we called project, using the communicativist terminology. Project examples can include decorating the classroom, a class of mathematics or physical education in the FL, preparing a breakfast party, a photographic contest, a trip with fun activities, interviewing an English-speaking resident, filming small reports or presentations about their school or village, organizing their correspondence with foreign students through an agency, producing surveys on their habits or tastes, a calendar with local events or even handicraft classes.

Although we understand that the material design in itself deserves further attention, we have only been able to set out a brief idea in this report. In the next section we describe how the experiment was designed, the procedures and the methods of data collection and some further description of the subjects.

\section{THE DESIGN OF THE EXPERIMENT}

The intention was to implement a course following our methodological guidelines with a group of learners during a whole school year. At the end of the year, the results obtained by the students would be compared to those obtained by another group with similar characteristics but following a different methodology. The experiment would be carried out in a scientific 
way and match what Seliger and Shohamy (1989, p.135) call experimental design, as it should include:

a) an experimental variable, here represented by the first group of learners,

b) a control or neutral group to compare the results with and

c) a longitudinal component, here represented by the nine month period of the school year.

For the control group, we selected an alternative methodology from among those habitual in our classrooms, which were for the most part eclectic, and used one of the manuals available on the market basically characterized by:

- the use of the L2 without excluding the L1.

- the conscious learning of grammar in the classroom.

- the division of the course into nine lessons, each one approaching eight different sections from an explicit syllabus, namely, oral production, listening, reading, writing, grammar, phonetics, vocabulary and speech functions.

For the experiment, we chose two class groups of 28 students out of the six groups already existing in our school for that year and we used information from their previous school records to ensure that both groups displayed similar academic skills. Relocating students from their original classes for the sake of homogeneity would not have added reliability to our research. Most of the students were aged 14 except six of them who were between 13 and 16. They were full-time ESL pupils at a secondary school in Spain and they all belonged to native Spanish families. Most of them had begun studying English at school at the age of 8 , except five of them who started at some point between 6 and 11 years old. Nevertheless, the entrance tests showed that the average child had just beginners' abilities, especially in speaking skills.

As the groups had been chosen randomly, we were unable to use absolute measures to compare them so we measured their progress instead. To quantify the degree of linguistic development experimented by the learners in both groups during the course, it was decided to measure before and after the experiment:

- their degree of oral comprehension

- their degree of oral production, and

- the syntactic complexity in the learners' oral production.

For that purpose we decided to elaborate two guided interviews, an initial and a final one, as the most valid and reliable method of evaluating the learners' oral production ${ }^{11}$. The interviews were recorded and transcribed. The increase in comprehension was measured by calculating the difference between the number of questions answered during the interview at the beginning and at the end of the experiment. The improvement in oral production was

${ }^{11}$ Weir $(1988$, p.22) widely considers the validity and reliability of this test method. 
calculated by noting the difference in the number of words per minute in their answers. Finally, the increase in the syntactic complexity of their oral production was the difference in the number of adjective and adverb phrases they used in both interviews.

Additionally, we also tried to measure progress in their learning skills by means of a series of writing tests designed to evaluate their grammatical and lexical knowledge, as well as their writing skills. We considered as learning practice those exercises that allow learners to monitor their production, that is to say, the use of conscious reflection on language. For the design of the writing tests we followed reliability criteria and used methods demanding a single answer, such as fill-in-the gap, transformation, cloze and sentence order tasks. Validity criteria were also used testing just one item in the syllabus at a time. To measure writing skills we decided to use a set of open-answer questions and evaluate them using a holistic scale. Inter-tester reliability did not present any apparent problems as the same teacher gave both courses and checked all the tests.

Likewise, we decided to take notes in the classroom during the year to describe learners' behaviour, namely:

- the number of written compositions they gave in during the year,

- the number of times that learners volunteered to come out to the blackboard,

- their initiative in the use of English for oral interaction,

- the hours previous to the course that the learners admitted to have given to English classes and

- their previous school record.

Finally, as it was considered to be the most influential individual factor for success in linguistic development in the classroom, a test of motivation was drawn up to interpret both groups' attitude towards the course. The devised test follows the work of Clement, Dörnyei, and Noel (1994), who examine in depth the psycho-social approximation to the construct of motivation, particularly in the FL classroom ${ }^{12}$.

The hypothesis was that the Experimental Group would develop a higher increase in oral comprehension and production skills. Besides, provided the time taken by the experiment proved to be long enough, it was expected that the Experimental Group would also develop more internal grammar than the Control Group and surpass the Control Group in the increase of syntactic complexity in their oral production. We expected that to be so because, other things being equal, the practices to which the Experimental Group would be exposed would help them develop the oral comprehension and production strategies necessary to activate natural processes of acquisition. The fact that opportunities for exposure to additional input for FL learners are far less probable than those of an L2 learner, contributed to the reliability of the results.

${ }^{12}$ For a similar approximation to motivation in the FL classroom see Madrid (1999). 


\section{Results}

After calculating the results obtained in the interviews, we could see that as for oral comprehension, the Experimental Group increased their scores three times more than the Control Group (graph 4). From 56\% of questions answered in the interview at the beginning of the course, they went on to answer $72 \%$ in the final one. The Control Group increased only from $62 \%$ to $67 \%$.

Graph 4. Percentage of questions answered.

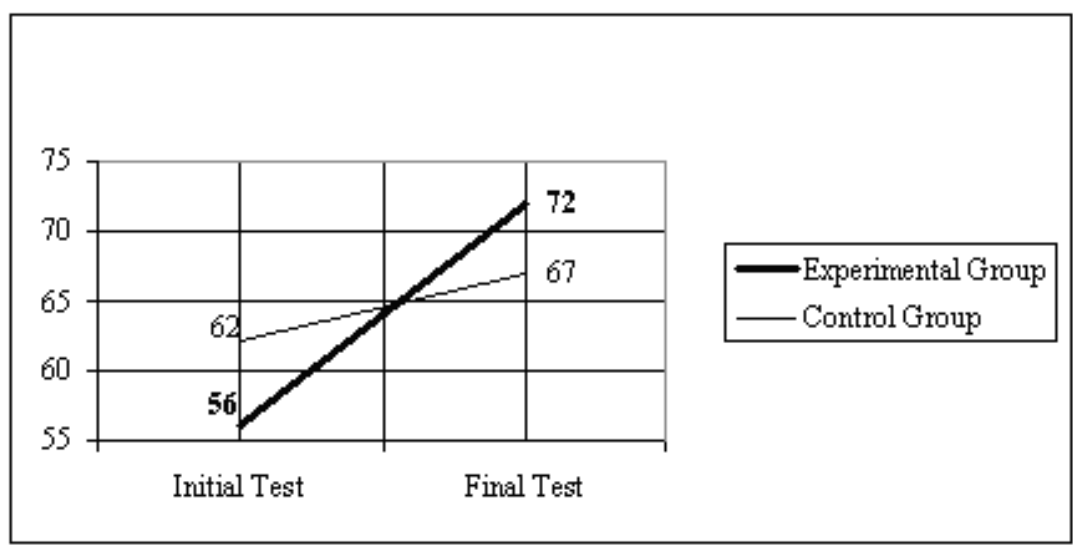

With regard to oral production, the Experimental Group increased their results up to four times more than the Control Group (graph 5). They went from 14 words per minute to 22.8, whereas the Control Group only went from 21.9 to 23.9.

Graph 5. Number of words per minute.

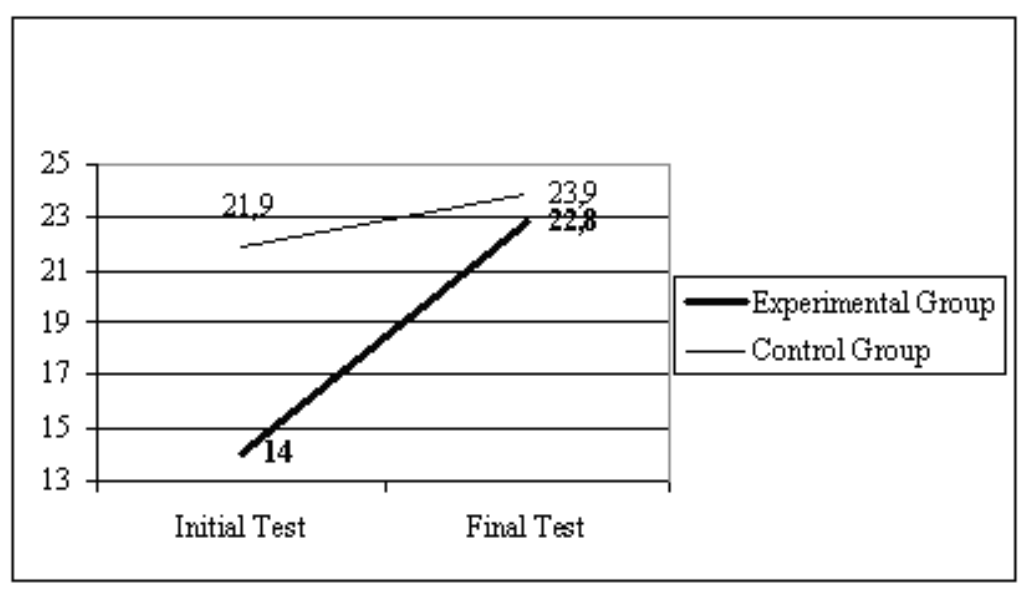


As for the syntactic complexity in their answers, the Experimental Group increased the number of adjective and adverb constructions used, almost doubling the results obtained by the Control Group (graph 6), going from 0.9 constructions per minute to 2.6, whereas the control group only went from 1.7 to 2.5 .

Graph 6. Number of adjective and adverb phrases per minute.

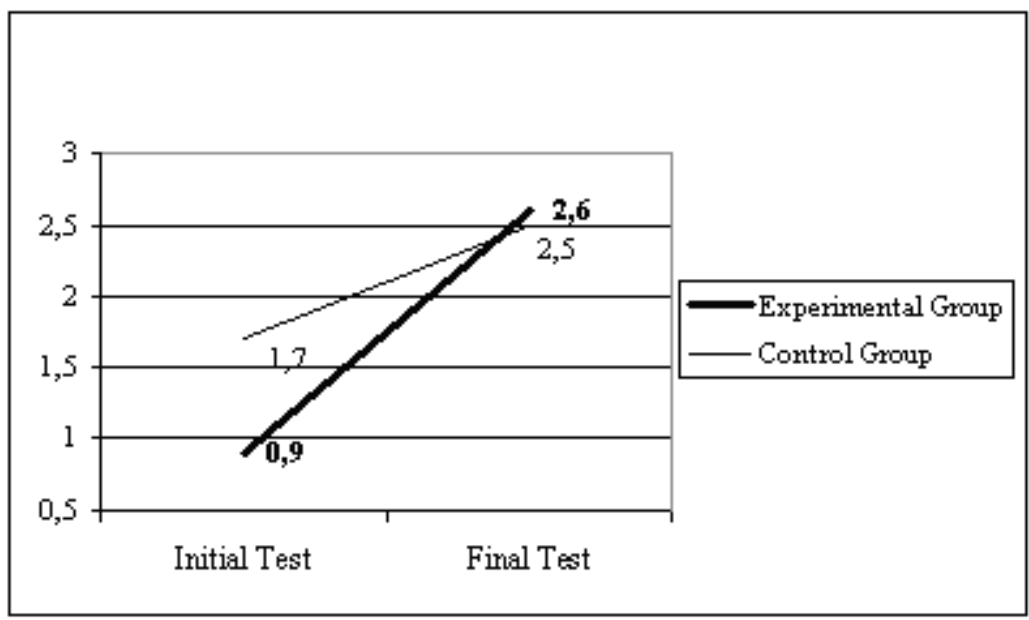

Regarding the results in the writing test, which was devised to measure knowledge in monitoring situations, they showed that the Experimental Group did not lose their capacity for conscious reflection in comparison with the Control Group (graph 7). In fact, by the end of the year, they overtook the Control Group, by a narrow margin.

Graph 7. Written tests scores in a scale of 10

\begin{tabular}{ccc} 
& $\begin{array}{c}\text { Experimental } \\
\text { Group }\end{array}$ & $\begin{array}{c}\text { Contol } \\
\text { Group }\end{array}$ \\
\hline 1st Written Test (Septenter) & 4.1 & 4.3 \\
7th Written Test (Jume) & 6.1 & 6.0
\end{tabular}

The motivation test consisted of a questionnaire made up of 57 questions grouped around the different factors which we considered were better able to describe the construct of motivation in FL development contexts. The results (see graph 8) point out: 
Graph 8. Results on the motivation test on a scale of 5.

\begin{tabular}{|c|c|c|}
\multicolumn{1}{|c}{ Construct Factors } & $\begin{array}{c}\text { Experimental } \\
\text { Group }\end{array}$ & $\begin{array}{c}\text { Control } \\
\text { Group }\end{array}$ \\
\hline Previous Experiences & 26 & 2.7 \\
\hline Personal Expectations & 39 & 2.7 \\
\hline School Expectations & 39 & 3.0 \\
\hline Effort & 3.1 & 3.3 \\
\hline Attitude & 36 & 3.0 \\
\hline Xerofilic Orientation & 43 & 3.1 \\
\hline Socio-Cultural Orientation & 33 & 2.3 \\
\hline Instrumertal Oriertation & 36 & 3.1 \\
\hline MediaUse Orientation & 38 & 3.0 \\
\hline Irtegrative Oniertation & 32 & 2.8 \\
\hline Couse Evahuation & 40 & 3.3 \\
\hline S elf-Confidence & 40 & 3.5 \\
\hline A VERAGE & 36 & 3.0 \\
\hline
\end{tabular}

- the high level of acceptance with which the students received the course, especially in contrast with their previous experiences.

- the outstanding degree of cohesion $^{13}$ among the learners in the Experimental Group at the end of the year.

- the need to discard the integrative and the socio-cultural orientation ${ }^{14}$ as sources of motivation in the context of FLA,

- the learners' degree of self-confidence, as well as their 'personal expectations ${ }^{15}$, appeared as the most determinant factors of progress ${ }^{16}$, confirming the importance that we had granted to the treatment of motivation.

${ }^{13}$ Cohesion inside a group of learners was a main component of the construct of motivation we used as it specially favours the opportunities for oral interaction in the classroom. This concept was included in the test into the course evaluation factor.

${ }^{14}$ In fact the socio-cultural orientation had already been discarded before the implementation of the test. Being loyal to the theoretical interpretation proposed, only immediate reference-full contexts should be considered, so that it makes no sense to include references to the Anglo-Saxon culture in the course syllabus in early phases of linguistic development. policies.

${ }^{15}$ In the construct used, the self-confidence factor is also related to error-treatment and evaluation

${ }^{16}$ These were the factors which better correlated with the results of the students who achieved a higher progress. 
Finally, we considered it interesting to also define the profile of the learners who benefited the most from the experimental course. For this, we correlated, by using Pearson's correlation coefficient, the three measurements of oral progress taken from the interviews, and the parameters from the notes taken in the classroom (see graph 9). This confirmed that it was precisely the least proficient learners in writing skills, with less outstanding school records, and with a less committed behaviour in the classroom who reached a higher increase in comprehension ${ }^{17}$. Evidently, these learners' profiles do not correlate any further with an increase in productive skills, for which a more active and compromising attitude is undoubtedly required.

\section{Graph 9. Correlational analysis between students' classroom data and oral skills progress.}

$\begin{gathered}\text { Notes from the Students who increased the } \\
\text { most in their results }\end{gathered}$
\begin{tabular}{|c|r|r|r|} 
IC & IP & ISC \\
Written Tests & -.28 & .25 & .35 \\
Previous Hours & .08 & .07 & .19 \\
School Records & -.07 & .53 & $\mathbf{. 4 6}$ \\
\hline Vohunteering for the Blaclboard & -.23 & .30 & .24 \\
\hline Iritiative in Use of Erglish & -.02 & .57 & .61 \\
\hline Compositions Handed in & -.13 & .21 & .16 \\
\hline
\end{tabular}

IC = Increase in Comprehension (Percentage of questions answered). IP = Increase in Production (Number of words per minute). ISC = Increase in Syntactic Complexity (Number of adjective and adverb phrases per minute).

The number of hours previously dedicated to English did not correlate, indicating a possible lack of functionality in the methodologies they had been exposed to before, as those methodologies, for some reason, had not favoured progress ${ }^{18}$. Another parameter without correlation to progress in linguistic development was the number of compositions the learners handed in. The intention was to measure the effort taken at home. The learners who worked the hardest at home were not among those who achieved a higher progress.

With regard to the attitude of volunteering for the blackboard, parameters correlate, but they correlate better with an increase in the amount of production than with syntactic complexity. This willing attitude of volunteering for the blackboard does not seem to represent the same effort as the following variable, namely measuring learners' initiative in the use of English in the classroom. The initiative in the use of English in the classroom was a parameter

${ }^{17}$ This measurement also shows the validity of these methodological guidelines for mixed-ability groups.

${ }^{18}$ In our research, the traditional system for evaluating FL learners' progress in Spanish secondary education is seriously criticized, as norm-referenced evaluation is unable to detect real progress. 
summing up the number of times that learners started up, on their own, oral interactions in the classroom using English. The learners who most reproduced this behaviour were those who achieved a higher increase in their oral production, as well as in syntactic complexity. Participating in interactions proved to be the clearest generator of linguistic knowledge.

The parameter that summarizes the learners' school records also correlates. Good students improved more than those with bad school records. This correlation is higher with regard to oral production than regarding syntactic complexity. In relation to syntactic complexity, the most decisive factor was the initiative in the use of English, over the aptitudes shown by learners or their school records. Finally, the school records correlated better with linguistic progress, both in oral production and in syntactic complexity, than with their results in the writing tests. This might indicate that the academic and/or cognitive aptitudes which determine progress in oral competence are different, and maybe of a more general nature, from those aptitudes related to writing competence.

\section{Conclusions}

We must admit that we regard these results as highly encouraging. The marked difference shown by both groups in the three measurements taken to evaluate linguistic development could reasonably indicate that the type of input to which the Experimental Group was exposed generated more linguistic development. Learners were able to infer new meanings across the context offered, and were able to activate mechanisms -additional mechanisms according to the author- to unfold new knowledge in FL with which the Control Group did not count.

Achieving these results despite the sparse attention given to the promotion of learning skills, leads us to believe that placing a greater emphasis on skills for learning may not be the way to induce natural language development. We therefore believe that learning skills should not bare a significant weight in the curriculum, even for students of these ages.

We are certain there were several factors which could have escaped our control, for example:

- As for motivation, did we place a greater emphasis in teaching on the Experimental Group? Did they feel they were the chosen group? How could this have influenced their performance?

- How far were our methods able to separate acquisition from learning outcomes?

There is no doubt that further inquiry is necessary. All in all, the analysis of the language comprehension processes that Relevance Theory provides, offers a clear step ahead in the interpretation of the internal processing of input also in SLA studies. RT considers these processes as inferential and describes the mechanisms to disambiguate the message and the conditions of access to meaning. This access is limited to the resources that learners have with which to corroborate their hypotheses, namely, their linguistic or general previous knowledge and their familiarity with the context. This way, the whole inferential process is governed by individual relevance and the law of least effort. All the methodological guidelines used in the experiment were orientated to underpin these factors. 
The characteristics of human language demand immersion to start the natural processes of inference that lead to comprehension. We can use other routes to accede to meaning, such as memory, linguistic reflection or habituation, but these are not the natural way. The consequence is a difference in the results as significant as those reached by this research.

The contribution of Ellis (1988) to the description of oral interaction in the classroom was especially valuable as communicative competence is an ability which cannot be acquired without exposure to interactive contexts.

Krashen's ideas certainly need to be revisited. Although the exposition of his postulates was not strictly scientific (Jordan 2004, p.178), his directives have marked the route for many later studies in SLA. Focusing mentalist studies on the characteristics of input was a solid contribution, especially to Applied Linguistics. In the end, apart from shaping the conditions of exposure to the FL, teachers cannot but provide the learner with the appropriate input. Although the distinction that Krashen proposes between acquisition and learning has actually been the object of profound disagreement, there is no doubt that any global attempt to describe the internal processes of linguistic development should take into account, at least, the degree of consciousness with which language is processed, the way memory intervenes and the role of previous knowledge. Given the difficulty to analyse the nature of each one of these, Krashen's dichotomous hypothesis assumes and solves the nature of linguistic internal processing in a descriptive, simple and especially practical way.

The results of this research support the initial idea that it is possible to generate acquisition in the FL classroom and also corroborate the functionality of the methodological proposals. They also seem to indicate that some of the current methodological guidelines, such as fomenting conscious reflection in the classroom, might be counter-productive to the development of natural comprehension skills.

\section{BibLiography}

Bialystok, E. (1988). "Psycholinguistic dimensions of second language proficiency", in Rutherford, W. and Sharwood-Smith, M. (eds.), Grammar and Second Language Teaching. Boston: Heinle \& Heinle Publishers, 31-50.

Bley-Vroman, R. (1988). "The fundamental character of foreign language learning”, in Rutherford, W. y Sharwood-Smith, M. (eds.), Grammar and Second Language Teaching. Boston: Heinle \& Heinle Publishers, 19-30.

Bocanegra Valle, A. (1995). Posibilidades del Empleo de una Metodología de Adquisición y Aprendizaje en el Caso de Estudiantes Universitarios de Inglés para Fines Específicos. Tesis Doctoral. Cádiz: Universidad de Cádiz.

Clément, R., Dörney, Z. and Noels, K.A. (1994). "Motivation, self-confidence, and group cohesion in the FL", in Language Learning, 44, 3: 417-48.

Corder, S.P. (1978). "Language distance and the magnitude of the learning task", in Studies in Second Language Acquisition, 2: 27-36.

Ellis, R. (1988). Classroom Second Language Development. Oxford: OUP.

Ellis, R. (1990). Instructed Second Language Acquisition. Oxford: Blackwell.

Felix, S. (1981). "The effect of formal instruction on second language acquisition", in Language Learning, 31, 1:87-112. 
García Jiménez, J. (2004). La Adquisición de una Lengua Extranjera en el Aula de la ESO. Tesis Doctoral. Cádiz: Universidad de Cádiz.

Haidl, A. (1993). "La Teoría de la Relevancia y los Procesos de Adquisición en la Enseñanza de Idiomas Extranjeros", in Pragmalingüística 1: 367-398. Cádiz: Universidad de Cádiz.

Haidl, A. (1995). Aportaciones a la Teoría de la Adquisición: una Metodología del Alemán para Universitarios Españoles. Tesis Doctoral. Cádiz: Universidad de Cádiz.

Haidl, A. (2003). Spracherwerb im Fremdsprachenunterricht in der Auslandssituation. Madrid: Editorial Idiomas.

Jordan, G. (2004). Theory Construction in Second Language Acquisition. Amsterdam: John Benjamins.

Krashen, S.D. (1981). Second Language Acquisition and Second Language Learning. Oxford: Pergamon.

Krashen, S.D. (1982). Principles and Practice in Second Language Acquisition. Oxford: Pergamon.

Larsen-Freeman, D. and Long, M.H. (1991). Introducción al estudio de la Adquisición de Segundas Lenguas. Madrid: Editorial Gredos.

Lightbown, P.M. (2000). "Classroom SLA Research and Second Language Teaching", in Applied Linguistics, 21, 4: 431-62.

Lee, W.R. (1979). Language Teaching Games and Contexts. Oxford: OUP.

McLaughlin, B. (1978). "The Monitor Model: some methodological considerations", in Language Learning, 28: 309-32.

Madrid, D (1999). La Investigación de los Factores Motivacionales en el Aula de Idiomas. Granada: Grupo Editorial Universitario.

Pienemann, M. (1984). "Psychological constraints on the teachability of languages", in Studies in Second Language Acquisition, 6, 2: 186-214.

Seliger, H.W. (1979). "On the nature and function of language rules in language teaching", in TESOL Quarterly, 13: 359-69.

Seliger, H.W. and Shohamy, E. (1989). Second Language Research Methods. Oxford: OUP.

Sharwood-Smith, M. (1981). "Consciousness-raising and the second language learner", in_Applied Linguistics, 2: 159-69.

Sperber, D and Wilson, D. (1984). "Pragmatics: an overview", in Georges, S. (ed.), From the Linguistic to the Social Context. Bolonia: Cooperativa Libraria Universitaria Editrice, 2141.

Ur, P. (1988). Grammar Practice Activities. CUP.

Weir, C.J. (1988). Communicative Language Testing. Exeter: University of Exeter.

Wode, H. (1981). "Language acquisition universals: A unified view of language acquisition", in Winitz, H. (ed.), Native Language and Foreign Language Acquisition. Annals of the NY Academic Sciences, 379: 218-34.

Wode, H. (1990). "Continuity in language acquisitional abilities", in Burmeister, H. and Rounds, P.L. (eds.), Variability in Second Language Acquisition. Proceedings of the $10^{\text {th }}$ Meeting of the Second Language Research Forum. Eugene: University of Oregon, 85-116.

Wright, A. (1995). Storytelling with Children. Oxford: OUP.

Zobl, H. (1985). "Grammars in search of input and intake", in Gass, S.M. and Madden, C. (eds.), Input and Second Language Acquisition. Rowley, MA: Newbury House, 329-44. 